\title{
Optimized geometry, vibration (IR and Raman) spectra and nonlinear optical activity of p-nitroanilinium perchlorate molecule: A theoretical study
}

\author{
Ömer TAmer ${ }^{1}$, Ahmet Sefa Atalay ${ }^{2}$, Davut Avci ${ }^{1}$, Yusuf Atalay $^{1 *}$, ErdoĞan Tarcan $^{3}$, \\ MARIUSZ K. MARCHEWKA ${ }^{4}$ \\ ${ }^{1}$ Sakarya University, Arts and Sciences Faculty, Department of Physics, 54187, Sakarya, Turkey \\ ${ }^{2}$ Sakarya University, Faculty of Engineering, Metallurgical and Materials Engineering, 54187, Sakarya, Turkey \\ ${ }^{3}$ Kocaeli University, Arts and Sciences Faculty, Department of Physics, 41380, Kocaeli, Turkey \\ ${ }^{4}$ Institute of Low Temperature and Structure Research, Polish Academy of Sciences, P.O. Box 937, 50-950 Wroclaw 2, Poland
}

\begin{abstract}
The molecular modeling of p-nitroanilinium perchlorate molecule was carried out by using B3LYP and HSEH1PBE levels of density functional theory (DFT). The IR and Raman spectra were simulated and the assignments of vibrational modes were performed on the basis of relative contribution of various internal co-ordinates. NBO analysis was performed to demonstrate charge transfer, conjugative interactions and the formation of intramolecular hydrogen bonding interactions within PNAPC. Obtained large dipole moment values showed that PNAPC is a highly polarizable complex, and the charge transfer occurs within PNAPC. Hydrogen bonding and charge transfer interactions were also displayed by small HOMO-LUMO gap and molecular electrostatic potential (MEP) surface. The strong evidences that the material can be used as an efficient nonlinear optical (NLO) material of PNAPC were demonstrated by considerable polarizability and hyperpolarizability values obtained at DFT levels.
\end{abstract}

Keywords: p-nitroanilinium perchlorate; IR and Raman spectra; DFT; nonlinear optics, natural bond orbital analysis; hydrogen bonding

(C) Wroclaw University of Technology.

\section{Introduction}

Nonlinear optical (NLO) materials have gathered great attention in recent years with respect to their potential applications in various fields, such as electro-optic modulation, frequency conversion, optical parametric oscillations, optical communication and optical computing [1-4]. In these fields, organic materials have some advantages over their inorganic counterparts, and it is stated that organic materials may eventually replace the inorganic ones in industrial applications [5]. The advantages of organic materials are that these materials have higher electronic susceptibility $(\chi)$ through molecular hyperpolarizability $(\beta)$, facile modification through standard synthetic methods and

*E-mail: yatalay@sakarya.edu.tr relative ease of device processing [6]. Hydrogen bonding, which has a directional nature can orient the molecules in a head-to tail manner, and it paves the way for the materials to exhibit NLO character. Additionally, the donor-acceptor systems show charge transfer between electron donating and withdrawing groups, leading to high molecular hyperpolarizability. Effective NLO materials have been obtained by the incorporation of highly active chromophore molecules which have a large molecular hyperpolarizability. All of the factors such as increased length, increased planarity and overall increased conjugation and the strength of donors and acceptors (i.e. the Hammett substituent-constant parameters) play important roles in nonlinear optics and are amenable to design of NLO complex. The aromatic molecules have received particular interest since they may exhibit large optical 
nonlinearities [7]. The polarizability of such systems can be enhanced through the rationalizing substitution with donor and acceptor groups to the opposite backbones of molecular systems. The title compound consists of p-nitroanilinium and perchlorate anion which are linked to each other through $\mathrm{N}-\mathrm{H} \cdots \mathrm{O}$ hydrogen bonds, formed by $\mathrm{H}$ atoms covalently bonded to the $\mathrm{N}$ atom. The nitro and ammonia groups are located at the opposite backbones of aromatic ring, and the molecular systems reveal strong hydrogen bonding interactions. The PNAPC molecule drew our attention due to the important and interesting properties. For example, the inter-molecular interactions such as hydrogen bonding have significant influences on linear and nonlinear optical properties of the molecules. Additionally, the microscopic origin of nonlinearity in the molecules is due to the presence of delocalized $\pi$ electron systems connecting donor and acceptor groups which enhance the necessary asymmetric polarizability. Keeping the above mentioned statements in mind, the PNAPC molecule was considered as a potential NLO material.

A number of papers reporting the theoretical and experimental investigations on the structure and vibration spectrum as well as the nonlinear optical efficiency of nitroanilinium compounds have appeared in the literature [8-12]. However, there is no theoretical study about the structure, vibrational assignments, electronic and nonlinear optical properties, natural bonding orbital analysis, molecular surfaces and Mulliken charges for p-nitroanilinium perchlorate molecule. In order to eliminate this deficiency, a series of quantum chemical calculations were performed by using density functional theory (DFT).

\section{Computational details}

The molecular modeling of the title molecule was carried out for only one p-nitroanilinium perchlorate molecule based on the crystal structure of the PNAPC taken from Cambridge Crystallographic Data Center (CCDC 757,132). All of the calculations were performed by using density functional theory (DFT) at Gaussian 09W program package [13], and the output files were visualized via Gaauss View 5 software [14]. The structural properties and vibration spectra of the PNAPC were determined through the applications of B3LYP and HSEH1PBE levels [15, 16] with the 6-311++G(d,p) basis set [17]. The assignments of vibration modes were performed on the basis of the relative contribution of various internal co-ordinates through the Gaussian $09 \mathrm{~W}$ software package with 'InternalModes' keyword. NBO analysis was performed to display interaction between the 'filled' donor-type NBO and 'empty' acceptor-type NBO in the molecule. The HOMO and LUMO energies, energy gap and related properties such as electronegativity, chemical hardness and softness were predicted at the same levels and basis set. DFT levels were also used to calculate the dipole moment $(\mu)$, the mean polarizability $(\alpha)$, the anisotropy of the polarizability $(\Delta \alpha)$, and the total first static hyperpolarizability $(\beta)$. Molecular electrostatic potential (MEP) surface and Mulliken charges were also investigated by using DFT levels.

\section{Results and discussion}

\subsection{Geometric optimization}

The p-nitroanilinium perchlorate crystal synthesized by Marchewka et al. crystallizes in $\mathrm{P} 2{ }_{1} / \mathrm{c}$ space group of monoclinic system with $\mathrm{a}=5.003$ (10) $\AA, b=10.685$ (2) $\AA, c=17.914$ (4) $\AA$, $\beta=94.44(3)^{\circ}$ and $Z=4$ [8]. The optimized structural parameters, bond length and bond angle calculated for p-nitroanilinium perchlorate molecule at B3LYP and HSEH1PBE levels using 6-311++G(d,p) basis set, compared with X-ray diffraction results are presented in Table 1 . The experimental structure with the labeling of atoms and theoretical optimized structure are given Fig. 1a and Fig. 1b, respectively.

The p-nitroanilinium perchlorate molecule has electron withdrawing nitro group and electron donating amino groups. Because of the electronic effects of push and pull type substituents the symmetry of the benzene ring is distorted. The electron donating substituents in the benzene ring, yield ring angles smaller than $120^{\circ}$ at the point of 
Table 1. Experimental and threotical bond lengths for p-nitroanilinium perchlorate.

\begin{tabular}{|c|c|c|c|c|c|c|c|}
\hline \multirow[b]{2}{*}{ Bond Lengths $(\AA)$} & \multirow[t]{2}{*}{ XRD [8] } & \multicolumn{2}{|c|}{ DFT } & \multirow[b]{2}{*}{ Bond Angles $\left({ }^{\circ}\right)$} & \multirow[t]{2}{*}{ XRD [8] } & \multicolumn{2}{|c|}{ DFT } \\
\hline & & B3LYP & HSEH1PBE & & & B3LYP & HSEH1PBE \\
\hline 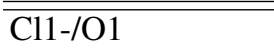 & 1.4355(9) & 1.4815 & 1.4638 & O2-/Cl1-/O4 & 109.99(6) & 110.311 & 110.410 \\
\hline $\mathrm{Cl1}-/ \mathrm{O} 2$ & $1.4419(9)$ & 1.5329 & 1.5138 & O3-/Cl1-/O4 & $110.72(6)$ & 110.312 & 110.122 \\
\hline $\mathrm{Cl1}-/ \mathrm{O} 3$ & $1.4420(9)$ & 1.5329 & 1.5094 & O5-/N2-/O6 & $123.49(11)$ & 125.309 & 125.535 \\
\hline Cl1-/O4 & $1.4133(9)$ & 1.4607 & 1.4441 & O6-/N2-/C4 & $118.43(10)$ & 117.395 & 117.283 \\
\hline $\mathrm{C} 1-/ \mathrm{N} 1$ & $1.4703(13)$ & 1.4635 & 1.4518 & O5-/N2-/C4 & $118.05(11)$ & 117.295 & 117.181 \\
\hline $\mathrm{N} 2-/ \mathrm{C} 4$ & $1.4756(15)$ & 1.4851 & 1.4747 & N2-/C4-/C3 & $118.68(11)$ & 118.993 & 118.960 \\
\hline $\mathrm{N} 2-/ \mathrm{O} 5$ & $1.2147(15)$ & 1.2229 & 1.2134 & $\mathrm{~N} 2-/ \mathrm{C} 4-/ \mathrm{C} 5$ & $119.16(11)$ & 118.631 & 118.567 \\
\hline N2-/O6 & $1.2092(14)$ & 1.2213 & 1.2119 & C3- & 122.1 & 122.376 & 122.472 \\
\hline N1-/H11 & $879(16)$ & 1.058 & 1.063 & $\mathrm{C} 4-\mathrm{I}$ & 121. & 119.913 & 119.743 \\
\hline N1-/H12 & 0.793 & 1.018 & 16 & C6- & 120 & 121.543 & 171.757 \\
\hline N1-/H13 & $0.901(15)$ & 1.058 & 1.056 & C4- & 118.7 & 118.544 & 118.495 \\
\hline $\mathrm{C} 1-/ \mathrm{C} 2$ & 1.3601 & 1.3927 & 1.3895 & C5-/ & 119.3 & 119.251 & 119.235 \\
\hline C2-/C3 & 1.376 & 1.3907 & 1.3868 & H6-/( & $118.8(8)$ & 120.906 & 120.856 \\
\hline C3-/C4 & 1.37 & 1.3903 & 1.3865 & C6- & 121.5 & 122.124 & 122.160 \\
\hline $\mathrm{C} 4-/ \mathrm{C} 5$ & 1.358 & 1.3890 & 1.3851 & C6-/ & $119.53(10)$ & 119.446 & 119.511 \\
\hline C5-/C6 & $1.3812(17)$ & 1.3905 & 1.3866 & C2-/ & $118.88(10)$ & 118.430 & 118.329 \\
\hline C1-/C6 & $1.3661(16)$ & 1.3905 & 1.3873 & $\mathrm{C} 4-/ \mathrm{C} 3-/ \mathrm{C} 2$ & $118.71(12)$ & 119.101 & 119.073 \\
\hline $\mathrm{C} 2-/ \mathrm{H} 2$ & $0.829(11)$ & 1.085 & 1.087 & H3-/C3-/C2 & 119.4(9) & 121.033 & 121.214 \\
\hline C4-/C3-/H3 & $121.8(9)$ & 119.866 & 119.714 & C3-/C2-/C1 & $119.47(12)$ & 118.604 & 118.566 \\
\hline C3-/H3 & $0.926(14)$ & 1.081 & 1.082 & C1-/C2-/H2 & $123.3(8)$ & 121.075 & 121.041 \\
\hline C5-/H5 & $0.867(12)$ & 1.080 & 1.082 & C3-/C2-/H2 & $117.2(8)$ & 120.321 & 120.393 \\
\hline C6-/H6 & $0.926(13)$ & 1.084 & 1.085 & C1-/N1-/H12 & $114.7(10)$ & 113.128 & 112.919 \\
\hline $\mathrm{R}^{2}$ & & 0.9524 & 0.9548 & C1-/N1-/H11 & $110.0(10)$ & 112.639 & 112.793 \\
\hline Bond An & & & & C1-/N1-/H13 & $110.8(10)$ & 113.127 & 112.904 \\
\hline$\overline{\mathrm{O} 1-/ \mathrm{Cl} 1-/ \mathrm{O} 2}$ & $109.70(5)$ & 108.613 & 108.729 & H12-/N1-/H13 & $109.5(13)$ & 109.788 & 110.235 \\
\hline O1-/Cl1-/O3 & $108.77(5)$ & 108.614 & 108.560 & H12-/N1-/H11 & $106.0(14)$ & 109.790 & 110.117 \\
\hline O1-/Cl1-/ & $110.18(6)$ & 113.022 & 112.989 & H13-/N1-/H11 & $105.3(13)$ & 97.372 & 96.811 \\
\hline $\mathrm{O} 2-/ \mathrm{C} 11-/ \mathrm{O} 3$ & $107.42(5)$ & 105.684 & 105.755 & $\mathrm{R}^{2}$ & & 0.8674 & 0.8588 \\
\hline
\end{tabular}

substitution and slightly larger than $120^{\circ}$ at the ortho and meta positions [18] and vice versa. The $\mathrm{C}-\mathrm{C}$ bond lengths observed in the region of 1.3588 to $1.3812 \AA$ [8] have been calculated in the ranges of 1.3890 to $1.3972 \AA$ and 1.3851 to $1.3890 \AA$ for B3LYP and HSEH1PBE levels, respectively. The $\mathrm{Cl}-\mathrm{O}$ bond lengths were observed in the range of 1.4133 to $1.4420 \AA$ [8], while these bond lengths have been calculated in the range of 1.4607 to $1.5329 \AA$ for B3LYP and 1.4441 to $1.5138 \AA$ for HSEH1PBE level. In our calculations, different $\mathrm{Cl}-\mathrm{O}$ bond lengths have been found for $\mathrm{ClO}_{4}$ group, since two $\mathrm{O}$ atoms (O12 and $\mathrm{O} 13)$ resonance in the hydrogen bonding $\mathrm{N}-\mathrm{H} \cdots \mathrm{O}$, led to an increase in $\mathrm{Cl}-\mathrm{O}$ bond lengths. Due to electron withdrawing nature of the nitro group, the bond angle at the point of $\mathrm{C} 3-\mathrm{C} 4-\mathrm{C} 5$ was found at $122.376^{\circ}$ and $122.472^{\circ}$, respectively. Similarly, at the point of attachment of electron donating amino group, the bond angle of C5-C6-C1 was calculated at $122.124^{\circ}$ and $122.160^{\circ}$, respectively. This demonstrates that the lone pair of electrons of the amino nitrogen is not delocalized into the ring, and is completely involved in the hydrogen bonding formation with $\mathrm{ClO}_{4}$ group. In order to compare results obtained at B3LYP and HSEH1PBE levels with X-ray results [8], the $\mathrm{R}^{2}$ values have been presented in Table 1 . According to these $\mathrm{R}^{2}$ values, HSEH1PBE level gives closer results in bond lengths, while B3LYP gives closer results in bond angles.

Theoretical calculations display the presence of two different intermolecular hydrogen bonding interactions in PNAPC molecule. One of these is 
Table 2. The theoretical and experimental $\mathrm{N} 1-\mathrm{H} 12 \cdots \mathrm{O} 2$ and $\mathrm{C} 2-\mathrm{H} 2 \cdots \mathrm{O} 2$ interaction parameters for $\mathrm{p}$ nitroanilinium perchlorate.

\begin{tabular}{llllll}
\hline & $\mathrm{D}-\mathrm{H} \cdots \mathrm{A}$ & $\mathrm{D}-\mathrm{H}(\AA)$ & $\mathrm{H} \cdots \mathrm{A}(\AA)$ & $\mathrm{D} \cdots \mathrm{A}(\AA)$ & $\mathrm{D}-\mathrm{H} \cdots \mathrm{A}\left({ }^{\circ}\right)$ \\
\hline \hline XRD & $\mathrm{N} 1-\mathrm{H} 12 \cdots \mathrm{O} 2$ & $0.793(14)$ & $2.242(14)$ & $2.9992(14)$ & $160.0(13)$ \\
& $\mathrm{C} 2-\mathrm{H} 2 \cdots \mathrm{O} 2$ & 0.829 & 2.642 & 3.262 & 132.7 \\
B3LYP & $\mathrm{N} 1-\mathrm{H} 12 \cdots \mathrm{O} 2$ & 1.058 & 1.718 & 2.660 & 145.5 \\
& $\mathrm{~N} 1-\mathrm{H} 13 \cdots \mathrm{O} 3$ & 1.058 & 1.718 & 2.660 & 145.5 \\
& $\mathrm{C} 2-\mathrm{H} 2 \cdots \mathrm{O} 1$ & 1.085 & 2.413 & 3.469 & 162.3 \\
HSEH1PBE & $\mathrm{N} 1-\mathrm{H} 12 \cdots \mathrm{O} 2$ & 1.063 & 1.662 & 2.662 & 147.3 \\
& $\mathrm{~N} 1-\mathrm{H} 13 \cdots \mathrm{O} 3$ & 1.056 & 1.714 & 2.641 & 143.7 \\
& $\mathrm{C} 2-\mathrm{H} 2 \cdots \mathrm{O} 1$ & 1.087 & 2.338 & 3.393 & 163.2 \\
\hline
\end{tabular}
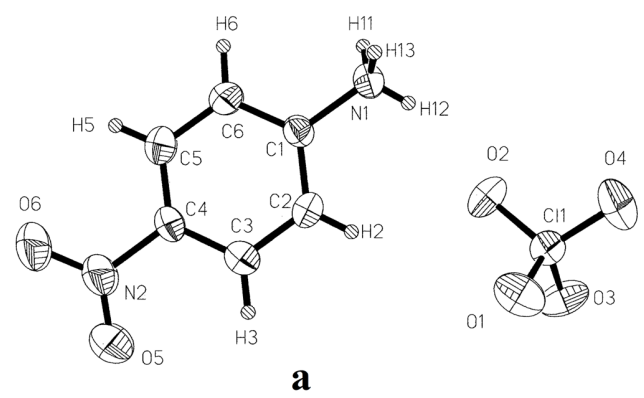

$\boldsymbol{a}$

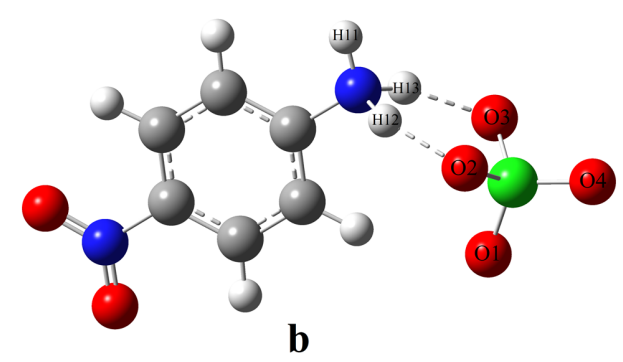

Fig. 1. (a) Experimental molecular structure, (b) optimized molecular structure of p-nitroanilinium perchlorate obtained at $\mathrm{B} 3 \mathrm{LYP} / 6-311++\mathrm{G}(\mathrm{d}, \mathrm{p})$ level.

between donor N1-H12 and acceptor O2 moieties, while the second one is between donor N1-H13 and acceptor $\mathrm{O} 3$ moieties (Table 2). These intermolecular hydrogen bonding interactions play a vital role in constructing of PNAPC crystals. In addition to these hydrogen bonding interactions, short $\mathrm{C}-\mathrm{H}$... O contacts predicted for PNAPC crystal are presented in Table 2.

\subsection{Vibrational assignments}

The IR and Raman spectra for PNAPC molecule have been simulated by using B3LYP

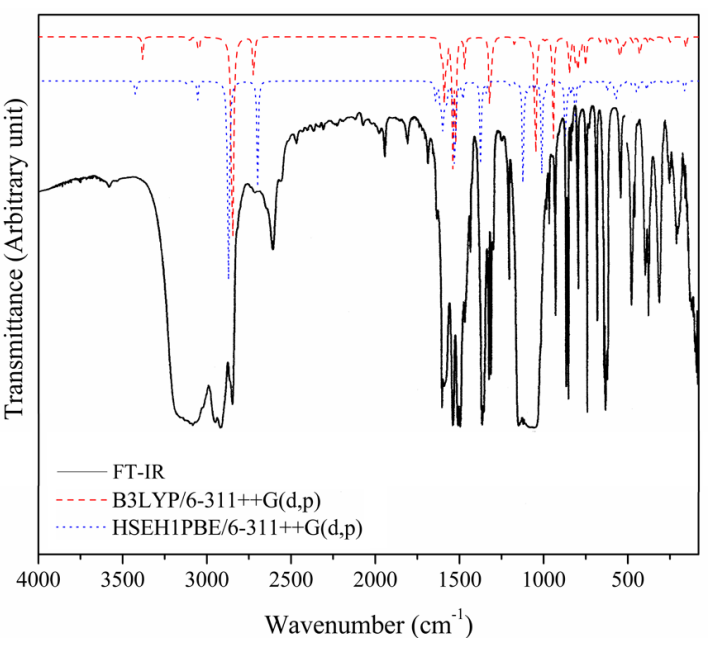

Fig. 2. The comparison of FT-IR and calculated IR spectra for p-nitroanilinium perchlorate.

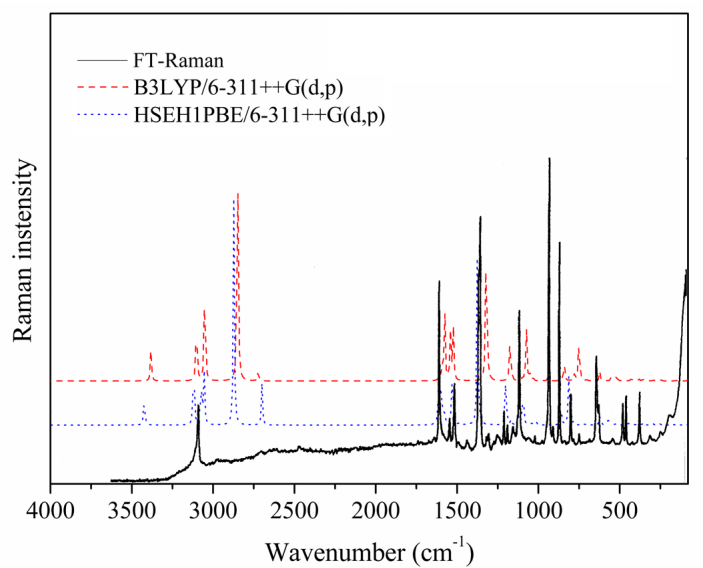

Fig. 3. The comparison of FT-Raman and calculated Raman spectra for $\mathrm{p}$-nitroanilinium perchlorate.

and HSEH1PBE levels and the obtained results are given in Fig. 2 and Fig. 3 as compared with FT-IR 
and FT-Raman results [8]. The calculated vibration frequencies, the percentage of relative contribution of various internal co-ordinates and approximate descriptions of normal modes are listed in Table 3. Frequency calculations at the same levels of theory revealed no imaginary frequencies, indicating that an optimal geometry at these levels of approximation was found for PNAPC. It is well known that DFT levels overestimate the vibration wavenumbers due to the neglecting of anharmonicity, lack of electron correlation effects and basis set deficiencies [19]. So, the scaling factor 0.9614 [20] was used providing closer results to the experimental ones [8].

\section{Hydogen bonding vibrations}

According to theoretical calculations, there are two types of intermolecular interactions (Table 3). The $\mathrm{NH}$ stretching vibration for $\mathrm{H}$ atom which does not involve hydrogen bonding is observed at $3155 \mathrm{~cm}^{-1}$, and this peak is calculated at 3381 and $3423 \mathrm{~cm}^{-1}$, for B3LYP and HSEH1PBE levels, respectively. The other NH stretching peaks for $\mathrm{H}$ atom involved in the hydrogen bonding interactions were observed at 2712 and $2646 \mathrm{~cm}^{-1}$ [8], and the corresponding peak in the Raman spectrum was observed at $2703 \mathrm{~cm}^{-1}$. These peaks were calculated as 2849 and $2722 \mathrm{~cm}^{-1}$ at B3LYP level, 2872 and $2700 \mathrm{~cm}^{-1}$ at HSEH1PBE level, respectively. Such a large shift between the NH stretching vibrations is due to weakening of bonds during rotation of the ammonio group involved in the hydrogen bonding interactions which bridges two atoms that have higher electronegativity (such as $\mathrm{O}$ and $\mathrm{N}$ ) than hydrogen. These $\mathrm{NH}$ stretching vibrations have the relative contribution of 84 to $78 \%$ to internal co-ordinates, and it can be said that these peaks are quite pure modes. The in-plane bending vibrations of $\mathrm{N}-\mathrm{H} \cdots \mathrm{O}$ group observed at 1425 and $1375 \mathrm{~cm}^{-1}$ in IR spectrum [8] have been found at 1539 and $1523 \mathrm{~cm}^{-1}$ with the relative contributions of 37 to $43 \%$ to internal co-ordinates for B3LYP, respectively. The peak belonging to out-ofplane bending of $\mathrm{N}-\mathrm{H} \cdots \mathrm{O}$ group was calculated at 992 and $1012 \mathrm{~cm}^{-1}$ as would be expected [8]. All of the in-plane and out-of-plane bending hydrogen bonding interactions were calculated as coupled modes (Table 3).

\section{Ring vibrations}

It is well known that aromatic ring $\mathrm{CH}$ stretching vibrations occur at 3100 to $2880 \mathrm{~cm}^{-1}$ [21]. The $\mathrm{CH}$ peaks observed in the region of 3135 to $3029 \mathrm{~cm}^{-1}$ [8] have been calculated in the range of 3102 to $3049 \mathrm{~cm}^{-1}$ for B3LYP level and 3120 to $3055 \mathrm{~cm}^{-1}$ for HSEH1PBE level. These peaks are approximately pure vibration modes with the contributions 81 to $72 \%$. Among these peaks, the lowest wavenumber is responsible for $\mathrm{C} 2-\mathrm{H} 2$ stretching vibration. This peak shifts to lower wavenumber due to the $\mathrm{C}-\mathrm{H} \cdots \mathrm{O}$ contact. The in-plane $\mathrm{CH}$ bending vibrations were calculated in the region of 1308 to $1056 \mathrm{~cm}^{-1}$ as mostly coupled modes, while out-of-plane ones were calculated in the region of 980 to $794 \mathrm{~cm}^{-1}$ by using B3LYP level. The CC stretching modes of the benzene ring are expected in the range from 1650 to $1200 \mathrm{~cm}^{-1}$. Marchewka et al. [8] reported the infrared bands at 1510,1496,1468, $1433 \mathrm{~cm}^{-1}$ and the Raman bands at 1509 and $1432 \mathrm{~cm}^{-1}$ were assigned to ring stretching type of vibrations. These CC peaks were calculated as coupled modes in the range of 1606 to $1163 \mathrm{~cm}^{-1}$ for B3LYP level and 1641 to $1167 \mathrm{~cm}^{-1}$ for HSEH1PBE level. In-plane $\mathrm{CC}$ bending vibration was calculated at $1056 \mathrm{~cm}^{-1}$, while out-of-plane bending was calculated at $1094 \mathrm{~cm}^{-1}$ by using B3LYP level with the relative contribution of $13 \%$.

\section{Nitro group vibrations}

In aromatic nitro compounds, symmetric and asymmetric stretching vibrations of $\mathrm{NO}_{2}$ group involved in the intra molecular charge-transfer give peaks in the range of 1570 to $1485 \mathrm{~cm}^{-1}$ and 1370 to $1320 \mathrm{~cm}^{-1}[22,23]$, respectively. These vibration peaks were observed at 1496 and $1241 \mathrm{~cm}^{-1}$, respectively, and the corresponding second peak in Raman spectrum was observed at $1246 \mathrm{~cm}^{-1}$ [8]. In our calculations, the asymmetric $\mathrm{N}=\mathrm{O}$ vibration was found at 1576 and $1597 \mathrm{~cm}^{-1}$ by using B3LYP and HSEH1PBE levels, respectively. The symmetric one was found at 1320 and $1374 \mathrm{~cm}^{-1}$ with the relative contribution of $44 \%$, respectively. 
Table 3. The selected theoretical and experimental vibration frequencies for p-nitroanilinium perchlorate.

\begin{tabular}{|c|c|c|c|c|c|c|c|c|}
\hline \multirow{2}{*}{$\begin{array}{l}\text { Assignments } \\
\left(\mathrm{B} 3 \mathrm{LYP} / 6-311++\mathrm{G}(\mathrm{d}, \mathrm{p})^{\mathrm{a}}\right.\end{array}$} & \multicolumn{2}{|c|}{ Experimental [8] } & \multicolumn{3}{|c|}{ B3LYP/6-311++G(d,p) } & \multicolumn{3}{|c|}{ HSEH1PBE/6-311++G(d,p) } \\
\hline & FT-IR & FT-Raman & $\begin{array}{l}\text { Scaled } \\
\text { Freq }^{\text {b }}\end{array}$ & $\mathrm{I}_{\mathrm{IR}}^{\mathrm{c}}$ & $\mathrm{I}_{\mathrm{R}}^{\mathrm{d}}$ & $\begin{array}{l}\text { Scaled } \\
\text { Freq }^{\mathrm{b}}\end{array}$ & $\mathrm{I}_{\mathrm{IR}}^{\mathrm{c}}$ & $\mathrm{I}_{\mathrm{R}}^{\mathrm{d}}$ \\
\hline$v \mathrm{NH} 84$ & 3155 & & 3381 & 59.42 & 66.00 & 3423 & 65.27 & 64.82 \\
\hline$v \mathrm{CH} 80$ & 3135 & & 3102 & 8.46 & 28.55 & 3120 & 9.11 & 48.29 \\
\hline$v \mathrm{CH} 81$ & 3103 & & 3101 & 6.36 & 109.61 & 3119 & 7.25 & 90.54 \\
\hline v $\mathrm{CH} 77$ & 3089 & 3090 & 3053 & 4.10 & 85.65 & 3075 & 2.99 & 86.25 \\
\hline$v \mathrm{CH} 72$ & 3029 & & 3049 & 54.22 & 114.18 & 3055 & 70.88 & 116.42 \\
\hline$v \mathrm{~N}-\mathrm{H} \cdots \mathrm{O} 80$ & 2712 & 2703 & 2849 & 1693.79 & 481.98 & 2872 & 1469.67 & 386.53 \\
\hline$v \mathrm{~N}-\mathrm{H} \cdots \mathrm{O} 78$ & 2646 & & 2722 & 146.04 & 19.59 & 2700 & 417.37 & 68.16 \\
\hline$v \mathrm{CC} 12+\beta \mathrm{NH} 332$ & 1605 & 1640 & 1606 & 61.92 & 12.01 & 1641 & 85.74 & 1.13 \\
\hline$v \mathrm{CC} 10+\beta \mathrm{NH} 329$ & 1591 & & 1589 & 229.50 & 17.63 & 1613 & 142.67 & 59.71 \\
\hline$v \mathrm{NO}_{2} 43$ & 1496 & & 1576 & 59.47 & 94.53 & 1597 & 238.16 & 64.33 \\
\hline$\beta$ HNH 69 & 1539 & 1538 & 1550 & 22.55 & 3.89 & 1579 & 125.16 & 25.92 \\
\hline$\beta \mathrm{CNH} 6+\beta \mathrm{N}-\mathrm{H} \cdots \mathrm{O} 37$ & 1425 & & 1539 & 422.80 & 57.07 & 1545 & 21.12 & 3.83 \\
\hline$\beta \mathrm{CNH} 7+\beta \mathrm{N}-\mathrm{H} \cdots \mathrm{O} 43$ & 1375 & & 1523 & 305.43 & 65.26 & 1528 & 496.23 & 81.48 \\
\hline$v$ CC 64 & 1468 & & 1470 & 73.80 & 3.08 & 1482 & 85.13 & 3.80 \\
\hline$v \mathrm{CC} 45$ & 1433 & 1432 & 1411 & 5.25 & 0.88 & 1424 & 5.42 & 0.63 \\
\hline$v \mathrm{NO}_{2} 44+v \mathrm{NC} 13+v \mathrm{CC} 10$ & 1241 & & 1320 & 289.36 & 212.00 & 1374 & 324.96 & 212.03 \\
\hline$v$ CC $32+\beta$ HCC 26 & 1312 & 1310 & 1308 & 47.29 & 7.08 & 1342 & 38.25 & 2.26 \\
\hline$\beta$ HCC $49+\beta$ HNC 6 & 1297 & 1298 & 1288 & 4.89 & 0.48 & 1285 & 1.95 & 0.46 \\
\hline$v \mathrm{CC} 13+v \mathrm{NC} 20$ & 1203 & 1204 & 1174 & 24.23 & 56.56 & 1200 & 16.75 & 62.64 \\
\hline$v \mathrm{CC} 15+v \mathrm{NC} 6+\beta$ HCC 62 & 1183 & 1183 & 1163 & 3.23 & 5.74 & 1167 & 8.02 & 5.15 \\
\hline$\beta$ HCC 30 & 1139 & & 1101 & 6.84 & 3.14 & 1123 & 443.92 & 11.72 \\
\hline$\beta \mathrm{HCC} 22+v$ NC 10 & 1121 & 1120 & 1074 & 16.18 & 66.37 & 1102 & 6.79 & 2.14 \\
\hline$\beta$ CCC $13+\beta$ HCC 19 & 1113 & 1111 & 1056 & 117.48 & 3.63 & 1094 & 47.15 & 48.10 \\
\hline$v \mathrm{ClO} 5+\beta \mathrm{CNH} 8$ & 1077 & & 1047 & 339.25 & 6.57 & 1058 & 31.99 & 0.52 \\
\hline$v \mathrm{ClO} 7+\beta \mathrm{CNH} 8$ & 1052 & 1052 & 1032 & 0.20 & 2.76 & 1041 & 2.64 & 2.92 \\
\hline$\beta \mathrm{CNH} 7+\gamma \mathrm{N}-\mathrm{H} \cdots \mathrm{O} 32$ & 980 & & 992 & 6.14 & 0.57 & 1012 & 353.55 & 3.20 \\
\hline$\gamma \mathrm{CCCC} 8+\gamma \mathrm{HCCC} 47+\gamma \mathrm{HCCN} 7$ & & & 980 & 0.19 & 0.01 & 994 & 25.77 & 0.56 \\
\hline$v \mathrm{ClO} 38$ & 928 & 928 & 944 & 330.79 & 3.37 & 984 & 1.50 & 0.01 \\
\hline $\begin{array}{l}\gamma \mathrm{HCCH} 16+\gamma \mathrm{CCCC} 15+\gamma \mathrm{HCCC} \\
30+\gamma \mathrm{HCCN} 16\end{array}$ & & & 943 & 0.66 & 0.05 & 946 & 0.06 & 0.04 \\
\hline$\gamma \mathrm{HCCC} 82+\gamma$ CCCC 10 & 850 & & 849 & 93.65 & 0.43 & 871 & 270.07 & 0.082 \\
\hline$\gamma \operatorname{CCCC} 14+\beta \mathrm{NO}_{2} 34$ & 863 & 864 & 841 & 37.26 & 21.72 & 860 & 36.31 & 24.98 \\
\hline$\gamma \mathrm{HCCC} 40+\gamma \mathrm{NCCH} 22+\gamma \mathrm{CCNH} 9$ & 831 & & 809 & 116.94 & 0.49 & 838 & 33.15 & 0.45 \\
\hline$\gamma \mathrm{HCCC} 25+\gamma \mathrm{NCCH} 12$ & 822 & & 794 & 83.55 & 0.31 & 813 & 129.19 & 50.19 \\
\hline$\gamma \mathrm{CCCC} 42$ & 792 & 793 & 777 & 31.60 & 7.76 & 805 & 2.23 & 0.49 \\
\hline$\gamma \mathrm{NO}_{2} 51$ & 739 & 741 & 749 & 104.24 & 51.85 & 788 & 18.51 & 3.15 \\
\hline$\gamma \mathrm{CCNO} 42+\gamma \mathrm{CCCC} 19$ & 722 & & 704 & 4.38 & 1.68 & 714 & 9.49 & 1.56 \\
\hline$\gamma \mathrm{CCNO} 24+\gamma \mathrm{CCCC} 20$ & 680 & & 662 & 18.38 & 0.03 & 670 & 15.98 & 0.09 \\
\hline
\end{tabular}

$\nu$, stretching; $\beta$, in-plane bending; $\gamma$, out-of-plane bending.

${ }^{a}$ Vibrational modes are based on PED and only contributions over $3 \%$ are given.

${ }^{\mathrm{b}}$ Scaled frequencies are in unit of $\mathrm{cm}^{-1}$.

${ }^{\mathrm{c}} \mathrm{I}_{\mathrm{IR}}$ infrared inten. are in unit of $\mathrm{km} \cdot \mathrm{mol}^{-1}$.

${ }^{\mathrm{d}} \mathrm{I}_{\mathrm{R}}$ Raman activ. are in unit of $\AA^{4} \cdot \mathrm{amu}^{-1}$.

The nitro group vibration peaks of PNAPC complex were found as very close to that of simple nitro compounds [24] due to the presence of nitro group in free state. According to "internal modes" analysis, in-plane bending vibration of nitro group was found at 841 and $860 \mathrm{~cm}^{-1}$, with the relative contribution of $34 \%$. The out-of-plane vibrations were found at 744 and $788 \mathrm{~cm}^{-1}$ with the relative contribution of $51 \%$. The $\mathrm{C}-\mathrm{N}$ stretching peak observed at $1203 \mathrm{~cm}^{-1}$ [8] is one of the most useful peaks for distinguishing individual nitro containing compounds, and this peak was found at 1174 
Table 4. Second-order perturbation theory analysis of Fock matrix in NBO basic corresponding to the intermolecular bonds for p-nitroanilinium perchlorate.

\begin{tabular}{|c|c|c|c|c|c|c|c|}
\hline \multirow[t]{2}{*}{ Donor (i) } & \multirow[t]{2}{*}{ Acceptor (j) } & \multicolumn{2}{|c|}{$\mathrm{E}(2)^{\mathrm{a}}(\mathrm{kcal} / \mathrm{mol})$} & \multicolumn{2}{|c|}{$E(j)-E(i)^{b}$ (a.u.) } & \multicolumn{2}{|c|}{$\mathrm{F}(\mathrm{i}, \mathrm{j})^{\mathrm{c}}$ (a.u.) } \\
\hline & & B3LYP & HSEH1PBE & B3LYP & HSEH1PBE & B3LYP & HSEH1PBE \\
\hline$\sigma(\mathrm{C} 1-\mathrm{C} 6)$ & $\sigma^{*}(\mathrm{C} 1-\mathrm{C} 2)$ & 4.34 & 4.55 & 1.29 & 1.30 & 0.067 & 0.069 \\
\hline$\sigma(\mathrm{C} 1-\mathrm{C} 6)$ & $\sigma^{*}(\mathrm{C} 5-\mathrm{C} 6)$ & 2.88 & 3.05 & 1.30 & 1.31 & 0.55 & 0.057 \\
\hline$\pi(\mathrm{C} 1-\mathrm{C} 6)$ & $\pi^{*}(\mathrm{C} 2-\mathrm{C} 3)$ & 17.30 & 16.26 & 0.31 & 0.31 & 0.066 & 0.064 \\
\hline$\pi(\mathrm{C} 1-\mathrm{C} 6)$ & $\pi^{*}(\mathrm{C} 4-\mathrm{C} 5)$ & 19.99 & 18.88 & 0.30 & 0.30 & 0.070 & 0.067 \\
\hline$\sigma(\mathrm{C} 4-\mathrm{C} 5)$ & $\sigma^{*}(\mathrm{C} 3-\mathrm{C} 4)$ & 4.64 & 4.91 & 1.29 & 1.30 & 0.069 & 0.071 \\
\hline$\sigma(\mathrm{C} 4-\mathrm{C} 5)$ & $\sigma^{*}(\mathrm{C} 5-\mathrm{C} 6)$ & 2.56 & 2.71 & 1.29 & 1.30 & 0.051 & 0.053 \\
\hline$\pi(\mathrm{C} 4-\mathrm{C} 5)$ & $\pi^{*}(\mathrm{C} 1-\mathrm{C} 6)$ & 19.13 & 17.97 & 0.28 & 0.27 & 0.065 & 0.063 \\
\hline$\pi(\mathrm{C} 4-\mathrm{C} 5)$ & $\pi^{*}(\mathrm{C} 5-\mathrm{C} 6)$ & 20.61 & 19.61 & 0.30 & 0.29 & 0.071 & 0.069 \\
\hline$\pi(\mathrm{C} 4-\mathrm{C} 5)$ & $\pi^{*}(\mathrm{~N} 2-\mathrm{O} 5)$ & 24.48 & 21.51 & 0.15 & 0.16 & 0.059 & 0.059 \\
\hline LP(3) O6 & $\pi^{*}(\mathrm{~N} 2-\mathrm{O} 5)$ & 164.96 & 161.35 & 0.14 & 0.15 & 0.139 & 0.139 \\
\hline $\mathrm{LP}(3) \mathrm{O} 2$ & $\sigma^{*}(\mathrm{~N} 1-\mathrm{H} 12)$ & 19.61 & 13.49 & 0.62 & 0.56 & 0.100 & 0.078 \\
\hline $\mathrm{LP}(3) \mathrm{O} 3$ & $\sigma^{*}(\mathrm{~N} 1-\mathrm{H} 13)$ & 19.65 & 19.14 & 0.62 & 0.75 & 0.101 & 0.109 \\
\hline
\end{tabular}

${ }^{a} \mathrm{E}(2)$ means energy of hyperconjugative interactions (stabilization energy).

${ }^{\mathrm{b}}$ Energy difference between donor and acceptor $\mathrm{i}$ and $\mathrm{j}$ NBO orbitals.

${ }^{\mathrm{c}} \mathrm{F}(\mathrm{i}, \mathrm{j})$ is the Fock matrix element between $\mathrm{i}$ and $\mathrm{j}$ NBO orbitals.

and $1200 \mathrm{~cm}^{-1}$ for B3LYP and HSEH1PBE levels, respectively.

\section{$\mathrm{ClO}_{4}^{-}$anions vibrations}

Perchloric acid has one hydroxyl group and three double-bonded oxygen atoms on the central $\mathrm{Cl}$ atom. The loss of the hydroxyl proton results in a negative charge shared by the four oxygens. The intermolecular charge transfer from the donor to acceptor group can induce large deviation of both the molecular dipole moment and the molecular polarizability, and produce very active IR and Raman peaks. The $\mathrm{Cl}-\mathrm{O}$ stretching vibration for perchlorate anion observed at $928 \mathrm{~cm}^{-1}$ was calculated at 944 and $984 \mathrm{~cm}^{-1}$ by using B3LYP and HSEH1PBE levels with the relative contribution of $38 \%$.

\subsection{NBO analysis}

NBO analysis is used to provide a clear description of the stabilizing interactions between filled (donor) and empty (acceptor) orbitals and destabilizing interactions between filled orbitals [25], and it could enhance the analysis of intra- and intermolecular interactions. NBO theory also allows the assignment of the hybridization of atomic lone pairs and of the atoms involved in bond orbitals. The hyperconjugative interaction energy was deduced from the second-order perturbation approach [26, 27]. For each donor (i) and acceptor (j), the stabilization energy $\mathrm{E}^{(2)}$ associated with the delocalization $\mathrm{i} \rightarrow \mathrm{j}$ is estimated as:

$$
E^{(2)}=\Delta E_{i j}=q_{i} \frac{F(i, j)^{2}}{\varepsilon_{i}-\varepsilon_{j}}
$$

where $q_{i}$ is the donor orbital occupancy, $\epsilon_{j}$ and $\epsilon_{i}$ the diagonal elements and $F(i, j)$ is the off diagonal NBO Fock matrix element. NBO analysis was performed to elucidate the intramolecular, hybridization and delocalization of electron density within PNAPC by using B3LYP and HSEH1PBE levels with the $6-311++\mathrm{G}(\mathrm{d}, \mathrm{p})$ basis set. The second order perturbation theory analysis of Fock matrix in NBO shows strong intermolecular hyper conjugative interactions presented in Table 4. In NBO analysis, the larger energy values of hyper conjugative interactions $(\mathrm{E}(2))$, the more intensive is the interaction between electron donors and electron acceptors, i.e. the more donating tendency from electron donors to electron acceptors, the greater the extent of conjugation of the whole system. NBO analysis indicates the strong intramolecular hyperconjugative interactions formed by the orbital overlap between bonding and antibonding orbitals, leading to inter and intramolecular charge transfer (Table 4). There occurs a strong intramolecular 
hyperconjugative interaction of $\pi$ electrons from (C4-C5) to $\pi^{*}$ (N2-O5) with the energy values of 24.48 and $21.51 \mathrm{kcal} / \mathrm{mol}$ at B3LYP and HSEH1PBE levels, respectively. The intramolecular hyperconjugative interaction of $\sigma$ (C1-C6) distributes to $\sigma^{*}(\mathrm{C} 1-\mathrm{C} 2)$ and (C5-C6), leading to stabilization of 4.34 and $2.88 \mathrm{kcal} / \mathrm{mol}$, respectively. This enhances further conjugation with antibonding orbital of $\pi^{*}(\mathrm{C} 2-\mathrm{C} 3)$ and $\pi^{*}$ (C4-C5) which leads to strong delocalization of 17.30 and $19.99 \mathrm{kcal} / \mathrm{mol}$, respectively. Interactions of the same kind were also calculated for PNAPC molecule (Table 4). These interactions resulted in molecular charge transfer causing stabilization of PNAPC, and the large hyperconjugative interaction energies values are the indicators of weakening of the respective bonds. NBO analysis clearly explains the formation of $\mathrm{H}$-bonded interaction between the $\mathrm{LP}(\mathrm{O})$ and $\sigma^{*}(\mathrm{~N}-\mathrm{H})$ antibonding orbitals. The stabilization energies $\mathrm{E}(2)$ associated with hyperconjugative interactions $\mathrm{LP}(3) \mathrm{O} 2 \rightarrow \sigma^{*}(\mathrm{~N} 1-\mathrm{H} 12)$ and $\mathrm{LP}(3)$ $\mathrm{O} 3 \rightarrow \sigma^{*}(\mathrm{~N} 1-\mathrm{H} 13)$, were equal to 19.61 and $19.65 \mathrm{kcal} / \mathrm{mol}$, which quantify the extent of intermolecular hydrogen bonding (Table 4).

\subsection{Nonlinear optical studies}

Density functional theory calculations have been proven to be a useful tool in the description of the relation among the electronic structure and its NLO response of a molecular system. The DFT approach allows the definition of molecular NLO properties as an inexpensive way to design molecules by analyzing their potential and determine the hyperpolarizability tensors of molecules before synthesis of the molecules [28, 29]. The significance of the polarizability and the first hyperpolarizability of a molecular system depends on the efficient electronic communication between donating and withdrawing groups, due to the fact that it is the basis to intramolecular charge transfer [30]. The intramolecular charge transfer from the donating to the withdrawing group through a conjugated path can induce large variations in both the molecular dipole moment and molecular polarizability, making IR and Raman activity strong at the same time [31]. Furthermore, the molecular hyperpolarizability can be enhanced in organic molecules by substitutions with $\mathrm{NH}_{3}$ and $\mathrm{NO}_{2}$ groups, which are involved in hydrogen bond interactions. The $\mathrm{N}=\mathrm{O}, \mathrm{C}=\mathrm{C}$ and $\mathrm{N}-\mathrm{H}$ stretching vibrations were calculated as strong and simultaneously active in IR and Raman spectra. So, the calculated stretching vibrations clearly demonstrate the presence of charge transfer interactions in PNAPC, making highly polarizable molecule. The first hyperpolarizability $(\beta)$, dipole moment $(\mu)$ and polarizability $(\alpha)$ were calculated using B3LYP and HSEH1PBE 6-311++G(d,p) basis set on the basis of the finite-field approach [3234]. Dipole moment of a molecule was used to study the intermolecular interactions. Additionally, dipole moment as a reflector of the molecular charge distribution can be used as descriptor to depict the charge movement across the molecule depending upon the centers of positive and negative charges. The dipole moment for PNAPC molecule were calculated as 7.244 and 7.216 Debye by using B3LYP and HSEH1PBE levels, respectively. Theoretical values indicate that dipole moments are dominant in the $\mathrm{x}$ and $\mathrm{y}$ directions but negligible in $\mathrm{z}$ direction. The magnitude of the molecular polarizability $(\alpha)$ and hyperpolarizability $(\beta)$ are the important key factors in a NLO system. The computed $\beta$ values of PNAPC were found as $11.272 \times 10^{-30}$ and $10.220 \times 10^{-30}$ esu by using B3LYP and HSEH1PBE levels, respectively. Urea and PNA were the prototypical molecules used in the study of the NLO properties of molecular systems and are frequently used as a threshold value for comparative purposes [35-37]. Obtained hyperpolarizability values are given in Table 5, in comparison with urea and PNA. From Table 5, the PNAPC molecule exhibits significant NLO character as compared with urea and PNA molecules [35]. Therefore, the PNAPC complex might be a potential excellent nonlinear optical material. The NLO results also indicate the electrons of the studied molecule can be easily polarized with changing environments such as lights and fields.

\subsection{Frontier molecular orbitals (FMOs)}

The frontier molecular orbitals play an important role in the electric and optical properties 
Table 5. Total static dipol moment ( $\mu$, in Debye), the mean polarizability $\left(\langle\alpha\rangle\right.$, in $\left.10^{-24} \mathrm{esu}\right)$, the anisotropy of the polarizability $\left(\Delta \alpha\right.$, in $\left.10^{-24} \mathrm{esu}\right)$, the mean first-order hyperpolarizability $\left(\langle\beta\rangle\right.$, in $\left.10^{-30} \mathrm{esu}\right)$ for p-nitroanilinium perchlorate.

\begin{tabular}{lcc}
\hline Property & B3LYP/6-311++G(d,p) & HSEH1PBE/6-311++G(d,p) \\
\hline \hline$\mu_{\mathrm{x}}$ & -4.940 & -4.911 \\
$\mu_{\mathrm{y}}$ & 5.288 & 5.277 \\
$\mu_{\mathrm{z}}$ & -0.318 & -0.313 \\
$\mu$ & 7.244 & 7.216 \\
$\alpha_{\mathrm{xx}}$ & 26.782 & 26.077 \\
$\alpha_{\mathrm{yy}}$ & 19.729 & 19.336 \\
$\alpha_{\mathrm{zz}}$ & 11.703 & 11.349 \\
$<\alpha>$ & 19.405 & 18.921 \\
$\Delta \alpha$ & 48.193 & 46.937 \\
$\beta_{\mathrm{xxx}}$ & -11.267 & -10.218 \\
$\beta_{\mathrm{yyy}}$ & 0.177 & 0.138 \\
$\beta_{\mathrm{zzz}}$ & 0.265 & 0.120 \\
$<\beta>$ & 11.272 & 10.220 \\
$<\beta>$ (pNA) & & \\
$<\beta>$ (Urea) & \multicolumn{3}{|}{} \\
\hline
\end{tabular}

Table 6. The frontier orbital energies, electronegativity, hardness and softness for p-nitroanilinium perchlorate.

\begin{tabular}{lcc}
\hline & B3LYP/6-311++G(d,p) & HSEH1PBE/6-311++G(d,p) \\
\hline \hline EHOMO $_{\text {HeV })}$ & -8.2281 & -8.1285 \\
$\mathrm{E}_{\text {LUMO }}(\mathrm{eV})$ & -3.6830 & -3.7505 \\
$\Delta \mathrm{E}$ & 4.5451 & 4.3780 \\
$\chi(\mathrm{eV})$ & 5.9555 & 5.9395 \\
$\eta(\mathrm{eV})$ & 2.2725 & 2.1890 \\
$\mathrm{~S}_{\left(\mathrm{eV}^{-1}\right)}$ & 0.2200 & 0.2284 \\
\hline
\end{tabular}

for of molecular systems. The HOMO represents the ability to donate an electron, while LUMO represents the ability to accept an electron. The small energy gap between the HOMO and LUMO leads to efficient electronic charge transfer from donating groups to withdrawing groups, making the molecule highly polarizable.

According to Fig. 4, HOMO is mainly localized over the perchlorate group, however LUMO is characterized by a charge distribution on nitroanilinium group. So, the HOMO $\rightarrow$ LUMO transition implies an electron density transfer from perchlorate to the remaining parts of PNAPC complex. The HOMO and LUMO were simulated by using B3LYP and HSEH1PBE levels, and illustrations obtained at B3LYP level are presented in Fig. 4. The HOMO and LUMO energies were calculated as -8.2281 and $-3.6830 \mathrm{eV}$ at B3LYP level, -8.1285 and $-3.7505 \mathrm{eV}$ at HSEH1PBE level, respectively (Table 6). The energy gap between the HOMO and LUMO were found as 4.5451 and $4.3780 \mathrm{eV}$. These energies indicate the lowering of energy gap and also reflect the NLO activity of PNAPC. Furthermore, the chemical hardness $(\eta)$ is a good indicator of the chemical stability. The soft molecules are more polarizable than the hard ones since they need small energy to excite one electron from a ground state to excited state. Electronegativity $(\chi)$ and chemical hardness $(\eta)$ can be calculated using the frontier molecular orbital energies $[38,39]$. The $\chi$ and $\eta$ values were calculated as 5.9555 and $2.2775 \mathrm{eV}$ at B3LYP level (Table 6). Consequently, PNAPC molecule is a polarizable complex and also can be used as an efficient NLO material. 


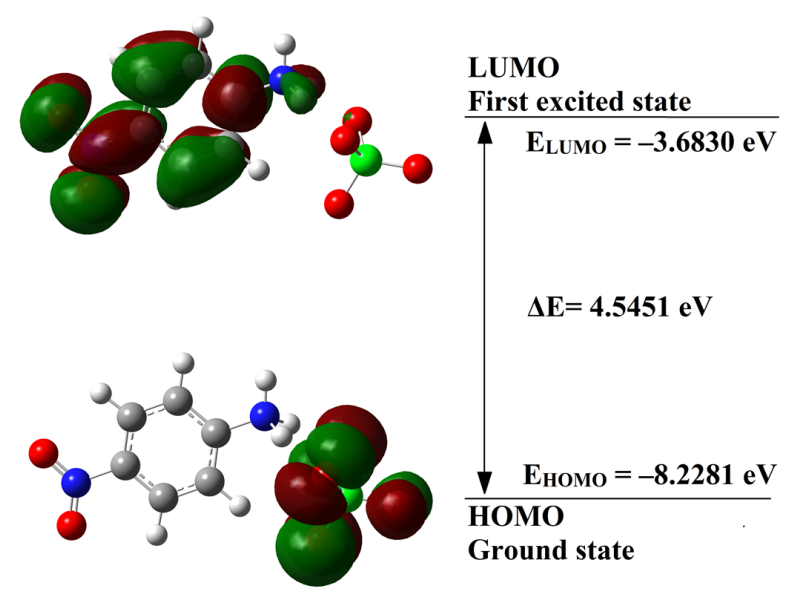

Fig. 4. Frontier molecular orbital pictures and energies for p-nitroanilinium perchlorate obtained at B3LYP/6-311++G(d,p).

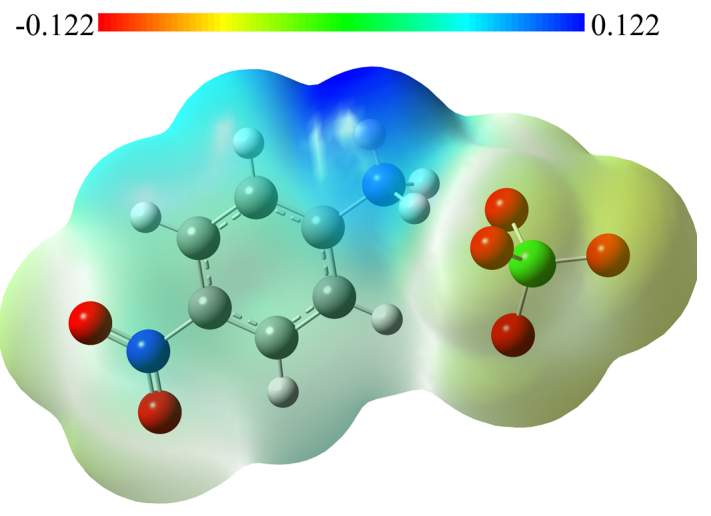

Fig. 5. 3D plot of molecular electrostatic potential (MEP) surface for $\mathrm{p}$-nitroanilinium perchlorate obtained at B3LYP/6-311++G(d,p).

\subsection{Molecular surfaces}

The molecular electrostatic potential (MEP) is a very useful descriptor for determining reactive sites for electrophilic and nucleophilic reactions as well as hydrogen-bonding interactions [40]. It is well known that MEP simultaneously displays molecular size, shape as well as positive, negative and neutral electrostatic potential region. The color scheme for the MEP surface is red (electronrich or partially negative charge), blue (electrondeficient or partially positive charge), light blue

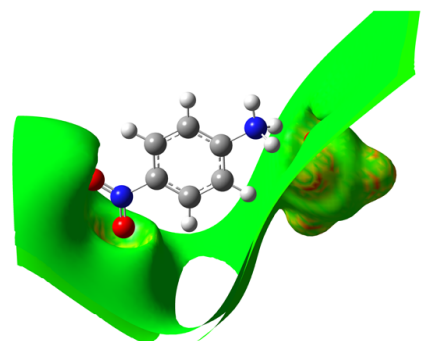

(a)

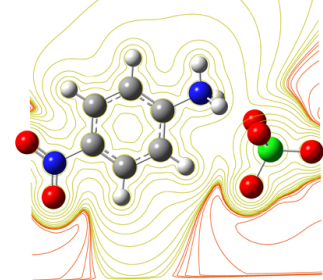

(b)
Fig. 6. 3D plot of electrostatic surface potential (ESP) and contour plot of ESP (blue) for p-nitroanilinium perchlorate obtained at B3LYP/6-311++G(d,p) level.

(slightly electron-deficient region), yellow (slightly electron-rich region), respectively. Areas of low potential, red, are characterized by an abundance of electrons. Areas of high potential, blue, are characterized by a relative absence of electrons. The MEP surface for PNAPC was simulated at B3LYP/6$311++\mathrm{G}(\mathrm{d}, \mathrm{p})$ basis set, and depicted in Fig. 5 .

As can be seen from the MEP surface of PNAPC, while the regions having the most negative potential are over the perchlorate group, oxygen and chloride atoms with a maximum value of -0.122 a.u., the regions having the most positive potential are over the hydrogen atoms of ammonia group with a maximum value of +0.122 a.u. So, the MEP clearly indicates the formation of the intermolecular hydrogen bonding interactions. In Fig. 5, the negative MEP is also localized over nitrogen and oxygen atoms of the nitro group and is reflected as a yellowish color, while the positive MEP is localized over the ring of hydrogen atoms and is reflected as bluish. This is an expected behavior, since electrostatic potential correlates with electronegativity and partial charges. The electrostatic surface potential (ESP) and the contour plot of ESP were simulated by using B3LYP/6$311++\mathrm{G}(\mathrm{d}, \mathrm{p})$ level. The polarization effect is also visible in these illustrations as can be seen in Fig. 6 .

\subsection{Mulliken atomic charges}

The Mulliken atomic charge is directly related to the vibrational properties of the molecular 


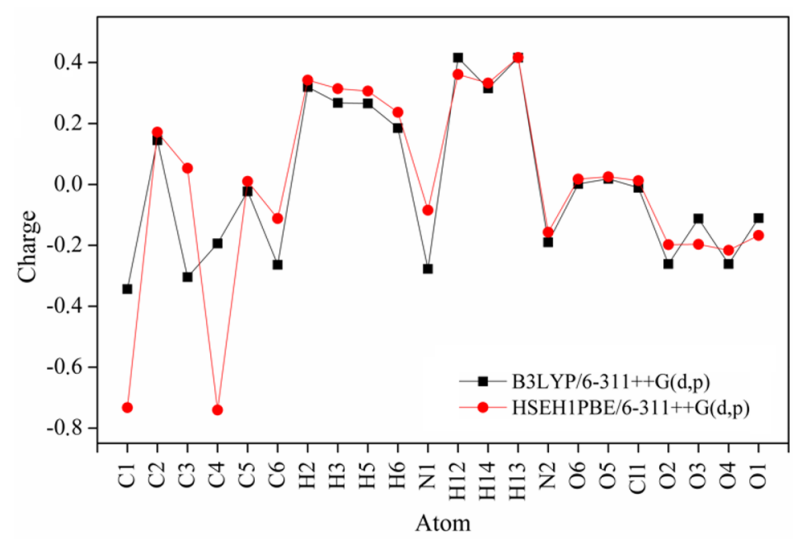

Fig. 7. Comparative of Mulliken atomic charges for pnitroanilinium perchlorate obtained at B3LYP and HSEH1PBE levels with 6-311++G(d,p) basis set.

systems, and explains how the electronic structure changes under atomic displacement; it is therefore related directly to the chemical bonds present in the molecule [41]. It affects dipole moment, polarizability, electronic structure and much more properties of molecular systems.

Mulliken atomic charges calculated at the B3LYP and HSEH1PBE levels with the 6-311++G $(d, p)$ are collected in Fig. 7. The maximum negative charge belongs to $\mathrm{O} 2$ and $\mathrm{O} 3$ atoms and its value is -0.541 . The maximum positive charge belonging to $\mathrm{Cl}$ atom is 1.128 . The atomic charges of all hydrogen atoms in the $\mathrm{NH}_{3}$ group are positive. The atomic charges of two hydrogen atoms involved in the hydrogen bonding interaction are 0.323 , while the third is 0.266 . So, the $\mathrm{H}$ atoms involved in the hydrogen bonding interactions have higher positive charge than the third one. These charge variations clearly reveal the existence of $\mathrm{N}-\mathrm{H} \cdots \mathrm{O}$ intermolecular hydrogen bonding. The electron withdrawing character of $\mathrm{NO}_{2}$ group in PNAPC is demonstrated by the decrease of electron density on ring carbon atom. The $\mathrm{N} 1$ atom has negative charge, while the $\mathrm{N} 2$ atom has positive charge due to the electronegativity of oxygen atoms. From Fig. 7, the carbon atoms have either positive or negative charges between -0.054 and 0.128 , while all of the ring hydrogen atoms have positive charge.

\section{Conclusions}

The optimized molecular geometry as well as the IR and Raman spectra were obtained at B3LYP and HSEH1PBE levels of density functional theory (DFT). The obtained structural and vibrational results can replace the experimental ones. Due to hydrogen bonding interactions between nitroanilinium and perchlorate moieties, PNAPC was oriented in a head-to tail manner, leading to an improvement of nonlinear optical properties. Some reductions in the wavenumbers of NH stretching vibrations was defined and that was an indicator of hydrogen bonding interactions within PNAPC. Additionally, it was demonstrated that the donating and withdrawing groups also contribute to NLO properties of PNAPC. The calculated vibration frequencies, the relative contributions to internal coordinates and approximate descriptions of normal modes were performed using Gaussian 09W. The obtained strong peaks responsible for the $\mathrm{N}=\mathrm{O}$, $\mathrm{C}=\mathrm{C}$ and $\mathrm{N}-\mathrm{H}$ stretching vibrations were highly active in IR and Raman spectra. These active peaks can improve the NLO properties of PNAPC by increasing polarizability of PNAPC. The strong intramolecular hyperconjugative interactions were found in NBO analysis, leading to inter and intramolecular charge transfers. The negative regions are mainly localized on the perchlorate group while the positive region is over ammonia group hydrogens. Accordingly, the MEP confirms the existence of intermolecular $\mathrm{N}-\mathrm{H} \cdots \mathrm{O}$ interactions observed in the solid state.

\section{References}

[1] Munn R.W., Ironside C.N., Principles, Applications of Nonlinear Optical Materials, Chapman \& Hall, London, 1993.

[2] Kaino T., Cai B., Takayama K., Adv. Funct. Mater. 12 (2002), 599.

[3] PRASAD P.N., Williams D.J., Introduction to Nonlinear Optical Effects in Molecules and Polymers, Wiley, New York, 1991.

[4] Thakur M., Xu J., Bhowmilk A., Zhou L., Appl. Phys. Lett., 74 (1999), 635.

[5] Dalton L.R., Sullivan P.A., Bale D.H., Chem. Rev., 110 (2010), 25.

[6] Pecaut J., Lefur Y., Masse R., Acta Cryst. B, 49 (1993), 535.

[7] Levine B.F., Chem. Phys. Lett., 37 (1976), 516. 
[8] Marchewka M.K., Drozd M., Pietraszko A., Mater. Sci. Eng. B-Adv., 100 (2003), 225.

[9] Subhashini V., Ponnusamy S., Muthamizhchelvan C., Spectrochim. Acta A, 87 (2012), 265.

[10] Sudharsana N., Subramanian G., KrishnakuMar V., Nagalakshmi R., Spectrochim. Acta A, 97 (2012), 798.

[11] Selvakumar E., Chandramohan A., Anandha Babu G., Ramasamy P., J. Cryst. Growth, 401 (2014), 323.

[12] Arjunan V., Marchewka M.K., Pietraszko A., Kalaivani M., Spectrochim. Acta A, 97 (2012), 625.

[13] Frisch M.J., TRUCKS G.W., SCHLEgel H.B., Scuseria G.E., RobB, M.A., Cheeseman J.R., Scalmani G., Barone V., MenNUCCI B., PETERSSON G.A., NAKATSUJi H., CARICATO M., LI X., HRATChiaN H.P., IZMAYlov A.F., Bloino J., ZHENG G., SONNENBERG J.L., HADA M., EHARA M., TOYOTA K., FUKUdA R., HASEgaWA J., ISHIDA M., NAKAJIMA T., Honda Y., KitAO O., NAKAI H., Vreven T., Montgomery J.A., JR., Peralta J.E., Ogliaro F., Bearpark M., Heyd J.J., Brothers E., Kudin K.N., Staroverov V.N., Kobayashi R., NORMAND J., RaghaVACHARI K., RENDELl A., BURANT J.C., IYENGAR S.S., Tomasi J., Cossi M., Rega N., Millam M.J., Klene M., Knox J.E., Cross J.B., Bakken V., Adamo C., Jaramillo J., Gomperts R., StratMANn R.E., YAZYeV O., Austin A.J., CAMmi R., POMElli C., OChTERSKI J.W., MARTIN R.L., Morokuma K., Zakrzewsik V.G., Voth G.A., SAlvador P., DANNENBerg J.J., DAPPRICH S., DANIELS A.D., FARKAS Ö., Foresman J.B., ORTIZ J.V., Cioslowski J., Fox D.J., Gaussian 09, Rev. D.01, Gaussian Inc., Wallingford CT, 2009.

[14] Dennington R., Keith T., Millam J., GaussView, Ver. 5, Semichem Inc., Shawnee Mission, KS, 2009.

[15] Lee C., Yang W., Parr R.G., Phys. Rev. B, 37 (1988), 785.

[16] Becke A.D., J. Chem. Phys., 98 (1993), 5648.

[17] Frisch M.J., Pople J.A., Binkley J.S., J. Chem. Phys., 80 (1984), 3265.

[18] Wang Y., Saebar S., Pittman JR C.U., J. Mol. Struct. Theochem., 281 (1993), 91.

[19] Pople J.A., Scott A.P., Wong M.W., Radom L., Israel J. Chem., 33 (1993), 345.

[20] Foresman J.B., in: E. FRISCH (ED.), Exploring Chemistry with Electronic Structure methods: A Guide to Using Gaussian, Gaussian Inc., Pittsburg, PA, 1996.
[21] UÇAR İ., TAMER Ö., SARIBOGA B., BÜYÜKGÜNGÖR O., Solid State Sci., 15 (2013), 7.

[22] Colthup N.B., Daly L.H., Wiberly S.E., Introduction to Infrared and Raman Spectroscopy, Academic Press, New York, 1990.

[23] Tamer Ö., Dege N., Demirtaş G., Avci D., AtaLAY Y., Macit M., ŞAhIN S., J. Mol. Struct., 1063 (2014), 295.

[24] Oszust J., Talik Z., Pietraszko A., Marchewka M.K., BARAN J., J. Mol. Struct., 415 (1997), 53.

[25] Fleming I., Frontier Orbitals and Organic Chemical Reactions, Wiley, London, 1976.

[26] Reed A.E., Weinhold F., J. Chem. Phys., 78 (1983), 4066.

[27] Foster J.P., Weinhold F., J. Am. Chem. Soc., 102 (1980), 7211.

[28] KunduracioĞlu A., Tamer Ö., Avci D., Kani I., Atalay Y., Çetinkaya B., Spectrochim. Acta A, 121 (2014), 35.

[29] Burland D.M., Miller R.D., Walsh C.A., Chem. Rev., 94 (1994), 31.

[30] Prasad O., Sinha L., Misra N., Narayan V., KUMAR N., PATHAK J., J. Mol. Struct., 940 (2010), 82.

[31] Castiglioni C., Del Zoppo M., Zerbi G., J. Raman Spectrosc., 24 (1993), 485.

[32] Öner N., Tamer Ö., Avci D., Atalay Y., Spectrochim. Acta A, 133 (2014), 542.

[33] PIR H., GÜNAY N., TAMer Ö., AvCi D., Atalay Y., Spectrochim. Acta A, 112 (2013), 331.

[34] Tamer Ö., Dege N., Demirtas G., Avci D., AtaLAY Y., Macit M., Alaman AĞAR A., Spectrochim. Acta A, 117 (2014), 13.

[35] Cheng L.T., Tam W., Stevenson S.H., Meredith G.R., Rikken G., Marder S.R., J. Phys. Chem., 95 (1991), 10631.

[36] KaAtz P., Donley E.A., Shelton D.P., J. Chem. Phys., 108 (1998), 849.

[37] Adant C., Dupuis M., Bredas J.L., Int. J. Quant. Chem., 56 (2004), 497.

[38] Avci D., BaşoĞlu A., Atalay Y., Int. J. Quantum Chem., 111 (2011), 130.

[39] Avci D., Spectrochim. Acta A, 82 (2011), 37.

[40] Politzer P., Truhlar D.G. (Eds.), Chemical Applications of Atomic and Molecular Electrostatic Potentials, Plenum, New York, 1981.

[41] Mulliken R.S., J. Chem. Phys., 23 (1995), 1833.

Received 2015-03-18

Accepted 2015-11-05 